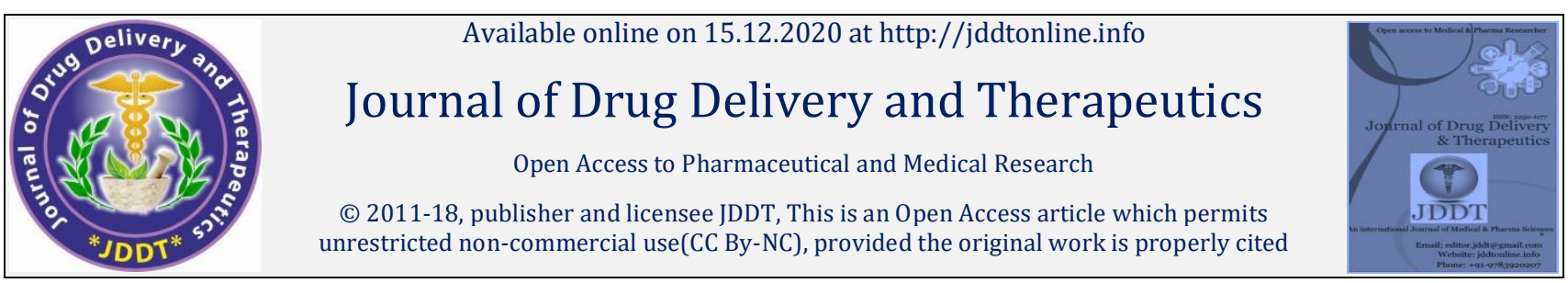

Open@Access

Research Article

\title{
Clinicopathologic Characteristics and Chemotherapy Response of Classic Hodgkin Lymphoma: A Study in Tertiary Teaching Hospital
}

\author{
Aryanti*, Bethy Surjawathy Hernowo, Hasrayati Agustina \\ Department of Anatomical Pathology, Faculty of Medicine, Hasan Sadikin General Hospital/ Padjadjaran University, Bandung, Indonesia
}

\begin{abstract}
Background and Objective: Hodgkin Lymphoma (HL) is known as a malignancy of the lymphatic system and $90 \%$ of the HL is Classic Hodgkin Lymphoma (CHL). Prognostic factors that identify the patient's response to therapy are useful for optimizing the therapy. This study aims to assess the clinicopathological characteristics and chemotherapy response associated with CHL patients.
\end{abstract}

Materials and Methods: This is a retrospective study of 40 patients diagnosed as CHL and treated with ABVD chemotherapy at Hasan Sadikin General Hospital/Padjadjaran University, Bandung, Indonesia during the period of January 2014 to December 2019. The clinicopathological characteristics data consisting of age, sex, histopathology subtype, tumor location and clinical stage were assessed. Their responses to chemotherapy were also analyzed.

Result and Discussion: A total of 40 patient data were included in this study, 21 CHL patients responded to ABVD chemotherapy (52.5\%) while 19 patients not responded (47.5\%). There were no significant association between age, sex, histopathological subtype, tumour location and clinical stage with chemotherapy response.

Conclusion: In this study, $47.5 \%$ of CHL patients did not respond to ABVD chemotherapy. The response of ABVD chemotherapy was not associated with age, sex, histopathological subtype, tumor location or clinical stage.

Keywords: Classic Hodgkin Lymphoma, chemotherapy response, clinicopathological characteristics.

Article Info: Received 07 Oct 2020; $\quad$ Review Completed 24 Nov 2020; $\quad$ Accepted 06 Dec 2020; Available online 15 Dec 2020

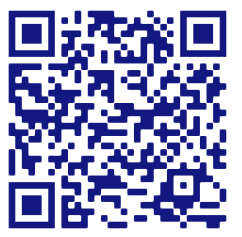

\section{Cite this article as:}

Aryanti, Hernowo BS, Agustina H, Clinicopathologic Characteristics and Chemotherapy Response of Classic Hodgkin Lymphoma: A Study in Tertiary Teaching Hospital, Journal of Drug Delivery and Therapeutics. 2020; 10(6-s):95-98 http://dx.doi.org/10.22270/jddt.v10i6-s.4638

*Address for Correspondence:

Aryanti, Department of Anatomical Pathology, Faculty of Medicine, Hasan Sadikin General Hospital/ Padjadjaran University, Bandung, Indonesia

\section{INTRODUCTION}

Hodgkin Lymphoma (HL) is a lymphoid neoplasm that generally occurs in the lymph nodes. HL consists of mononuclear and multinucleated cells with a background of mature, non-neoplastic inflammatory cells ${ }^{1}$. Based on data from the GLOBOCAN International Agency for Research on Cancer (IARC) in 2018, HL has an incidence rate of $0.44 \%$ of all malignant cases $^{2}$. In Indonesia, the percentage of new cases is $0.3 \%$ and the mortality rate is $0.28 \%{ }^{3}$.

Based on the histopathological appearance, HL is divided into 2 types known as Classic Hodgkin Lymphoma (CHL) which has Hodgkin-Reed-Sternberg (HRS) cells and the Nodular Lymphocyte Predominant Hodgkin Lymphoma (NLPHL) which is dominated by lymphocytes. CHL includes $90 \%$ of the total HL cases. CHL is subdivided into four main histologic subtypes: nodular sclerosis, mixed cellular, lymphocyte-rich and lymphocyte depleted ${ }^{1}$.

Patients who have been given first line chemotherapy (CT) in CHL have more than $80 \%$ of cases enter into complete remission, however up to $40 \%$ become relapses and about $10-25 \%$ experience refractory or unresponsive, thus requiring additional therapy ${ }^{4-6}$.

The patient's outcome can be determined by the characteristics of the disease. The presence of prognostic factors should help to stratify therapy according to risk profiles and predict which patients may fail therapy7. In developing countries, limited information is available on clinical, epidemiological, or response to the therapy. The current study aims to investigate clinicopathology figures and chemotherapy response in patients with CHL in our tertiary centre. 


\section{MATERIAL AND METHODS}

This research was a retrospective analytic-observational study of 40 patients diagnosed as CHL during in period 20142019 in Department of Anatomical Pathology, Hasan Sadikin General Hospital/Padjadjaran University, Bandung, Indonesia. The study group involved patients were aged from 13 to 76 years which consists of 22 males and 18 females. Ethical approval was given by the General Hospital. Clinicopathological parameters included in the analysis were age, sex, histological subtype, stage, tumour location and chemotherapy response. Data processing used the Statistical Package for Social Science (SPSS) software for Windows operating system.

The ABVD regimen was started initially in each patient regardless of staging status. Chemoteraphy response assessments were carried out after at least 4 cycles of CT. Patients that received radiotherapy were not included in the object of study. Complete Remission (CR) was defined as the complete regression of clinical and radiological lesions. Partial Response (PR) was defined as the reduction of the lesion size $\geq 30 \%$ from the total longest diameter of the target lesion. Progression of Disease (PD) was defined as increase by $\geq 20 \%$ of at least one measurable lesion, or by the appearance of a new lesion. Stable Disease (SD) was defined as decreased or increased size of lesions that do not qualify for $\mathrm{PR}$ or $\mathrm{PD}^{8}$. All cases were declared to respond to chemotherapy if they were included in the complete or partial response criteria, and as non-responsive if they were included in PD or SD criteria

\section{RESULTS}

Table 1 shows the patient characteristics, the mean age of 39 years. There are more subjects under 45 years of age. The male gender is more than the female. Most histopathology subtype was MCCHL (37.5\%). Most clinical stage is stage II (35\%). The most common tumor sites were nodal in $77.5 \%$.

All patients were evaluated for treatment response as shown in Table 2. After 4-cycles of CT, 21 patients (52.5\%) showed responsive groups (complete and partial response) and 19 patients $(47.5 \%)$ non-responsive groups (stable and progression). As shown in Table 2, there were association between the characteristics of study subjects by age, age category, sex, histopathological subtype and clinical stage in the responsive and nonresponsive groups. Numerical data analysis was tested by using unpaired $\mathrm{T}$ test.

The group of nonresponsive subjects result mean age value of 38 years. The age category $<45$ years has a higher percentage of $68.4 \%$. Gender is more common in women (57.9\%). Most histopathology subtype was MCCHL (42.1\%). For the most clinical stages, there are stages II and IV with the same percentage $(36.8 \%)$. While in the group that responded to chemotherapy, the most often was stage II. At tumor site, both groups were consistently nodal. The analysis in Table 2 shows a p-value greater than 0.05 , indicating no significant corelation between the characteristic variables of the research subjects and therapeutic response (p-value > 0.05).

Table 1. Characteristic of patients

\begin{tabular}{|c|c|}
\hline \multicolumn{2}{|c|}{ Variable $(\mathrm{N}=40)$} \\
\hline \multicolumn{2}{|l|}{ Age (year) } \\
\hline Mean \pm Std & $39.18 \pm 16.356$ \\
\hline \multicolumn{2}{|c|}{ Age category (year) } \\
\hline$<45$ & $26(65 \%)$ \\
\hline$\geq 45$ & $14(35 \%)$ \\
\hline \multicolumn{2}{|l|}{ Sex } \\
\hline Male & $22(55 \%)$ \\
\hline Female & $18(45 \%)$ \\
\hline \multicolumn{2}{|c|}{ Histopathological subtype } \\
\hline NSCHL & $13(32.5 \%)$ \\
\hline MCCHL & $15(37.5 \%)$ \\
\hline LRCHL & $8(20 \%)$ \\
\hline LDCHL & $4(10 \%)$ \\
\hline \multicolumn{2}{|l|}{ Stage } \\
\hline I & $4(10 \%)$ \\
\hline II & $14(35 \%)$ \\
\hline III & $12(30 \%)$ \\
\hline IV & $10(25 \%)$ \\
\hline \multicolumn{2}{|l|}{ Location } \\
\hline Nodal & $31(77.5 \%)$ \\
\hline Ekstranodal & $9(22.5 \%)$ \\
\hline
\end{tabular}


Table 2. Association of chemotherapy response on CHL with characteristic of patients (NR = Nonresponsive; $C R / P R=$ Complete response/ Partial response)

\begin{tabular}{|c|c|c|c|}
\hline \multirow[b]{2}{*}{ Variable } & \multicolumn{2}{|c|}{ Chemotherapy response groups } & \multirow[b]{2}{*}{ p-value } \\
\hline & $\begin{array}{c}\text { NR } \\
N=19\end{array}$ & $\begin{array}{c}\text { CR/PR } \\
N=21\end{array}$ & \\
\hline \multicolumn{3}{|l|}{ Age (year) } & 0.800 \\
\hline Mean \pm Std & $38.47 \pm 15.756$ & $39.81 \pm 17.244$ & \\
\hline \multicolumn{3}{|l|}{ Age category (year) } & 0.666 \\
\hline$<45$ & $13(68.4 \%)$ & $13(61.9 \%)$ & \\
\hline$\geq 45$ & $6(31.6 \%)$ & $8(38.1 \%)$ & \\
\hline \multicolumn{3}{|l|}{ Sex } & 0.119 \\
\hline Male & $8(42.1 \%)$ & $14(66.7 \%)$ & \\
\hline Female & $11(57.9 \%)$ & $7(33.3 \%)$ & \\
\hline \multicolumn{3}{|c|}{ Histopathologic subtype } & 1.000 \\
\hline NSCHL & $6(31.6 \%)$ & $7(33.3 \%)$ & \\
\hline MCCHL & $8(42.1 \%)$ & $7(33.3 \%)$ & \\
\hline LRCHL & $4(21.1 \%)$ & $4(19.0 \%)$ & \\
\hline LDCHL & $1(5.3 \%)$ & $3(14.3 \%)$ & \\
\hline \multicolumn{3}{|l|}{ Clinical stage } & 0.691 \\
\hline I & $1(5.3 \%)$ & $3(14.3 \%)$ & \\
\hline II & $7(36.8 \%)$ & $7(33.3 \%)$ & \\
\hline III & $4(21.1 \%)$ & $8(38.1 \%)$ & \\
\hline IV & $7(36.8 \%)$ & $3(14.3 \%)$ & \\
\hline \multicolumn{3}{|l|}{ Tumor location } & 0.583 \\
\hline Nodal & $14(73.7 \%)$ & $17(81.0 \%)$ & \\
\hline Ekstranodal & $5(26.3 \%)$ & $4(19.0 \%)$ & \\
\hline
\end{tabular}

\section{DISCUSSION}

CHL accounts for $90 \%$ of all Hodgkin lymphoma cases. Based on WHO data, the average age of CHL patients has a bimodal age distribution in early adulthood are 20-30 years and more than 55 years (advanced adults) ${ }^{1}$. The age of patients in this study were ranged from 13-76 years with a mean age of 39 years. The youngest age in this study was slightly lower than Gerber et al.'s research report, which represents the age range of 24-51 years ${ }^{9}$. CHL is more common in children in developing countries. While in developed countries, it is more dominated by young adults who occur increases with age 10 .

At age $\geq 45$ years, they were usually less response to chemotherapy due to the lack of ability to tolerate chemotherapy doses 7 . In this study, it was found that the variable age $\geq 45$ years had a number of cases that did not differ too much between the responded group and those who did not. There were 8 cases who responded, with age $\geq 45$ years ( 5 patients were under 60 years old). It was known that the response to chemotherapy decreases with age, especially $>60$ years due to more frequent use of comorbid diseases and the higher likelihood of toxicity ${ }^{11}$.
It was found that the highest number of cases were male patients $(55 \%)$, this is similar to the epidemiology in WHO and other studies 1, 9, 12. According to Moccia et al., male tended to be independently associated with a poorer outcome $^{13}$. However, women represented a higher percentage in the group who did not respond to chemotherapy in our study. The different responses of male and female to lymphoma may be due to differences in pharmacokinetics. Female patients were known to be more haematological toxicity, more often with leukopenia ${ }^{7}$.

The most histopathological subtype in this study was MCCHL at $37.5 \%$ and the second largest was NSCHL at $32.5 \%$. Similar results were obtained in a study conducted by Mozaheb et al. for Asian population, and the study of Konkay et al. in one of the institutions in India14, 15. This was consistent with previous studies which reported that MCCHL was more common in developing countries ${ }^{16}$. Whereas in western countries, the most subtypes were in the NSCHL subtype $^{1,17}$. It was shown that MCCHL was also the most common in the nonresponsive group, although it was not statistically significant. MCCHL is often associated with a poor prognosis, this was possible because MCCHL was more common in the elderly and was found at more advanced stages 4 . 
The result showed the most cases of CHL were included in stage II (35\%). This result was similar with previous study by Boo et al. in one hospital in Malaysia18. Based on a retrospective study in 3 hospitals in Saudi Arabia by Shafi et $a l$. , the results were slightly different. It showed $74 \%$ of cases were at stage III-IV ${ }^{19}$. This was possible due to the patient's lack of knowledge about lymphoma, so they did not immediately seek treatment when symptoms appeared. The lack of early detection of lymphoma in Indonesia has also affected the number of cases found at an early stage. CHL patients with an advanced stage, who had been given chemotherapy treatment, were associated with shorter progression free survival. It was related to patients who experience amplification of chromosome 9p24.1. It has been stated by previous studies, that increasing the amplification of chromosome 9p24.1 will increase the expression of PD-L1 on the surface of HRS cells, so that it is expected to have a better outcome after PD-1 blockade 4 .

The number of patients with nodal sites were more cases when compared to extranodal sites. In the $\mathrm{CHL}$, almost all cases were found in the lymph nodes, although in the course of the disease it can develop into extranodes. Extranodal invasion of adjacent tissues may occur in up to $15 \%$ of cases $^{20}$. The percentage of case responded to the chemotherapy regimen (CR/PR) in this study was lower than other study response 21-23. This difference was due to the number of the samples and includes radiotherapy as an adjunct therapy, which may have contributed to the successful response to therapy.

\section{CONCLUSION}

There were $47.5 \%$ of patients not responding to chemotherapy, with the most common histopathologic subtypes was MCCHL and stage II. There was no statistically significant association between clinicopathological characteristics with chemotherapy response.

\section{ACKNOWLEDGMENT}

The authors would like to thank to technicians of histopathology and immunohistochemistry laboratories, archivists of Medical Record Instalation of Hasan Sadikin General Hospital for all technical supports.

\section{CONFLICT OF INTEREST}

The authors declare that there are no conflict of interests in this study.

\section{REFERENCES}

1. Swerdlow SH., Campo E., Haris NL., Jaffe ES. Hodgkin Lymphoma. WHO Classification of Tumours of Haematopoietic and Lymphoid Tissues Lyon: International Agency for Research on Cancer Press 2017. p. 423-41.

2. Bray F, Ferlay J, Soerjomataram I, Siegel RL, Torre LA, Jemal A. Global cancer statistics 2018: GLOBOCAN estimates of incidence and mortality worldwide for 36 cancers in 185 countries. CA Cancer J Clin. 2018 Nov; 68(6):394-424.

3. GLOBOCAN. Indonesia. [database on the Internet] 2018. Available from: https://gco.iarc.fr/today/data/factsheets/populations/360indonesia-fact-sheets.pdf.

4. Ansell SM. Hodgkin lymphoma: 2018 update on diagnosis, risk-stratification, and management. Am J Hematol. 2018 May; 93(5):704-15.

5. Gerrie AS, Power MM, Shepherd JD, Savage KJ, Sehn LH, Connors JM. Chemoresistance can be overcome with high-dose chemotherapy and autologous stem-cell transplantation for relapsed and refractory Hodgkin lymphoma. Ann Oncol. 2014 Nov; 25(11):2218-23.

6. Kallam A, Vose JM. Hope After Salvage Therapy Fails: Novel Agents for Relapsed/Refractory Hodgkin Lymphoma. Oncology (Williston Park). 2019 May 14; 33(5):192-8.

7. Cuccaro A, Bartolomei F, Cupelli E, Galli E, Giachelia M, Hohaus S. Prognostic factors in hodgkin lymphoma. Mediterranean journal of hematology and infectious diseases. 2014; 6(1):e2014053-e.

8. Eisenhauer EA, Therasse P, Bogaerts J, Schwartz LH, Sargent D, Ford R, et al. New response evaluation criteria in solid tumours: revised RECIST guideline (version 1.1). Eur J Cancer. 2009 Jan; 45(2):228-47.

9. Gerber NK, Atoria CL, Elkin EB, Yahalom J. Characteristics and outcomes of patients with nodular lymphocyte-predominant Hodgkin lymphoma versus those with classical Hodgkin lymphoma: a population-based analysis. Int J Radiat Oncol Biol Phys. 2015 May 1; 92(1):76-83.

10. Sherief LM, Elsafy UR, Abdelkhalek ER, Kamal NM, Elbehedy R, Hassan TH, et al. Hodgkin lymphoma in childhood: clinicopathological features and therapy outcome at 2 centers from a developing country. Medicine. 2015 Apr; 94(15):e670.

11. Böll B, Görgen H. The treatment of older Hodgkin lymphoma patients. Br J Haematol. 2019 Jan; 184(1):82-92.

12. Huang X, Nolte I, Gao Z, Vos H, Hepkema B, Poppema S, et al. Epidemiology of classical Hodgkin lymphoma and its association with Epstein Barr virus in Northern China. PLoS One. 2011; 6(6):e21152.

13. Moccia AA, Donaldson J, Chhanabhai M, Hoskins PJ, Klasa RJ, Savage KJ, et al. International Prognostic Score in advancedstage Hodgkin's lymphoma: altered utility in the modern era. J Clin Oncol. 2012 Sep 20; 30(27):3383-8.

14. Mozaheb Z. Epidemiology of Lymphoid Malignancy in Asia. Epidemiology Insights, Maria de Lourdes Ribeiro de Souza da Cunha, IntechOpen. 2012.

15. Konkay K, Paul TR, Uppin SG, Rao DR. Hodgkin lymphoma: A clinicopathological and immunophenotypic study. Indian J Med Paediatr Oncol. 2016 Jan-Mar; 37(1):59-65.

16. Shanbhag S, Ambinder RF. Hodgkin lymphoma: A review and update on recent progress. CA: a cancer journal for clinicians. 2018; 68(2):116-32.

17. Younes A. Handbook of Lymphoma. Switzerland: Springer International Publishing 2016

18. Boo YL, Ting HSY, Yap DFS, Toh SG, Lim SM. Clinical features and treatment outcomes of Hodgkin lymphoma: A retrospective review in a Malaysian tertiary hospital. Blood Res. 2019; 54(3):210-7.

19. Shafi RG, Al-Mansour MM, Kanfar SS, Al Hashmi H, Alsaeed A, Al-Foheidi $M$, et al. Hodgkin Lymphoma Outcome: A Retrospective Study from 3 Tertiary Centers in Saudi Arabia. Oncology Research and Treatment. 2017; 40(5):288-92.

20. Guermazi A, Ooi CGG. Extranodal Hodgkin Disease. In: Guermazi A, editor. Radiological Imaging in Hematological Malignancies. Berlin, Heidelberg: Springer Berlin Heidelberg; 2004. p. 48-71.

21. Rueda Domínguez A, Márquez A, Gumá J, Llanos M, Herrero J, de Las Nieves MA, et al. Treatment of stage I and II Hodgkin's lymphoma with ABVD chemotherapy: results after 7 years of a prospective study. Ann Oncol. 2004 Dec; 15(12):1798-804.

22. Canellos GP, Anderson JR, Propert KJ, Nissen N, Cooper MR, Henderson ES, et al. Chemotherapy of Advanced Hodgkin's Disease with MOPP, ABVD, or MOPP Alternating with ABVD. 1992; 327(21):1478-84.

23. Gordon LI, Hong F, Fisher RI, Bartlett NL, Connors JM, Gascoyne RD, et al. Randomized phase III trial of ABVD versus Stanford V with or without radiation therapy in locally extensive and advanced-stage Hodgkin lymphoma: an intergroup study coordinated by the Eastern Cooperative Oncology Group (E2496). J Clin Oncol. 2013 Feb 20; 31(6):684-91. 